\title{
A very rare case of pancreatic head glomangiomyoma successfully treated by enucleation
}

\author{
Luis Cesar Bredt, Andre Keijy Kajimura Petri, Fernanda Matsue Ezure \\ Bredt, Ellan Giulianno Ferreira, Tiago Cesar Mierzwa, \\ Milton Neckel Junior
}

\begin{abstract}
Introduction: Glomangiomyoma or glomus tumor is a tumor of mesenchymal origin, usually benign forms of terminal glomus or glomus body, which is specialized form of arteriovenous anastomosis subcutanea with intervening in the regulation of blood flow and temperature. This tumor is extremely rare, and can be classified according to his histology in: glomangioma (60\%), solid glomus tumor (25\%), and glomangiomyoma (15\%). The glomangiomyoma is frequently located in the lower extremities and the treatment of choice for isolated this tumor is surgical excision. Pancreatic glomus tumors are quite rare, with only one case reported in English literature. Case Report: We report the second case in English literature of a glomangiomyoma in the pancreas of a 65-yearold male. The rarest variant of glomus tumor was $8 \mathrm{~cm}$ in diameter and the treatment consisted of tumor enucleation, the patient is alive with no evidence of recurrence 24 months after surgery. Conclusion: Glomangiomyoma is a tumor that mainly affects the lower limbs, but in rare cases, as reported, can affect other structures,
\end{abstract}

Luis Cesar Bredt ${ }^{1}$, Andre Keijy Kajimura Petri ${ }^{1}$, Fernanda Matsue Ezure Bredt' ${ }^{1}$, Ellan Giulianno Ferreira ${ }^{1}$, Tiago Cesar Mierzwa ${ }^{1}$, Milton Neckel Junior ${ }^{1}$

Affiliations: ${ }^{1} \mathrm{MD}$, Department of Abdominal Surgery, Hepatobiliary Section, Cancer Hospital-UOPECCAN, Cascavel, PR, Brasil.

Corresponding Author: Ellan Giulianno Ferreira, Adress: Rua Marechal Floriano, 3518, ap 102, Centro.Cascavel, Paraná, BRASIL. Postal Code: 85810-190; Ph: +55(45) 9946-6054; Fax: +55(45)2101-7005; Email: ellan@hotmail. com.br.

Received: 09 August 2013

Accepted: 12 September 2013

Published: 12 November 2013 as reported in the pancreatic head. The surgical treatment with enucleation is curative.

Keywords: Glomangiomyoma, Enucleation, Pancreatic head, Glomus tumor

\section{How to cite this article}

Bredt LC, Petri AKK, Bredt FME, Ferreira EG, Mierzwa TC, Junior MN. A very rare case of pancreatic head glomangiomyoma successfully treated by enucleation. Int J Hepatobiliary Pancreat Dis 2014;4:10-14.

Article ID: 100015IJHPDLB2014

$* * * * * * * * *$

doi:10.5348/ijhpd-2014-15-CR-3

\section{INTRODUCTION}

Glomangiomyoma or glomus tumor is a tumor of mesenchymal origin, usually benign forms of terminal glomus or glomus body, which is a specialized form of arteriovenous anastomosis subcutanea with intervening in the regulation of blood flow and temperature. Arising from modified smooth muscle cells or cells glomus, glomus artery segment or channel Sucquet Hoyer [1, 2]. The first detailed clinical description was made by William Wood in 1812, who described it as a subcutaneous tumor intensely painful, slow growing and susceptible to temperature variations. Years later in 1924, Pierre Masson described the histopathology and established histogenesis. They are classified into solitary (90\%) or multiple (10\%) the latter being sporadic or familiares [3]. The glomus body is an anatomical unit being distributed throughout the body, being situated in the deeper layers of the dermis and subcutaneous tissue preferably subungual 


\section{[4].}

It is an uncommon tumor, accounting for $1-5 \%$ of all soft tissue tumors of the hand, usually presents between the third and fourth decade of life, with a slight predominance of females (2:1) [5]. It is located in acral regions, particularly the subungual region of the fingers $(50-75 \%)$. However, these lesions may arise in areas devoid of extra-cutaneous glomus cells, such as stomach, colon, trachea, mediastinum, kidney, where it is postulated that the source of these tumors reside in the differentiation of pluripotent mesenchymal cells or smooth muscle cells or glomus common ectopic [5]. Glomus tumor of the pancreas is extremely rare, and there is only one case reported in English literature [6].

We report the second case in English literature of a pancreatic glomangiomyoma in a 65 years old man.

\section{CASE REPORT}

A 65-year-old male patient, presented with complaints of epigastric pains for about a year, with recent onset of postprandial vomiting and weight loss. The abdomen tomography demonstrated a well-defined lesion in pancreatic head with about $8 \mathrm{~cm}$, with extension to retroperitoneal region and apparent duodenal luminal obstruction without invasion of the superior mesenteric vessels and celiac trunk (Figure 1), and endoscopic ultrasonography confirmed the absence of tumoral invasion of vascular structures and duodenum.

The surgical exploration revealed a well-defined nodular lesion in the pancreatic head, about $8 \mathrm{~cm}$ in diameter, soft consistency, surface pink, bright, partial duodenal obstruction by compression, without invasive

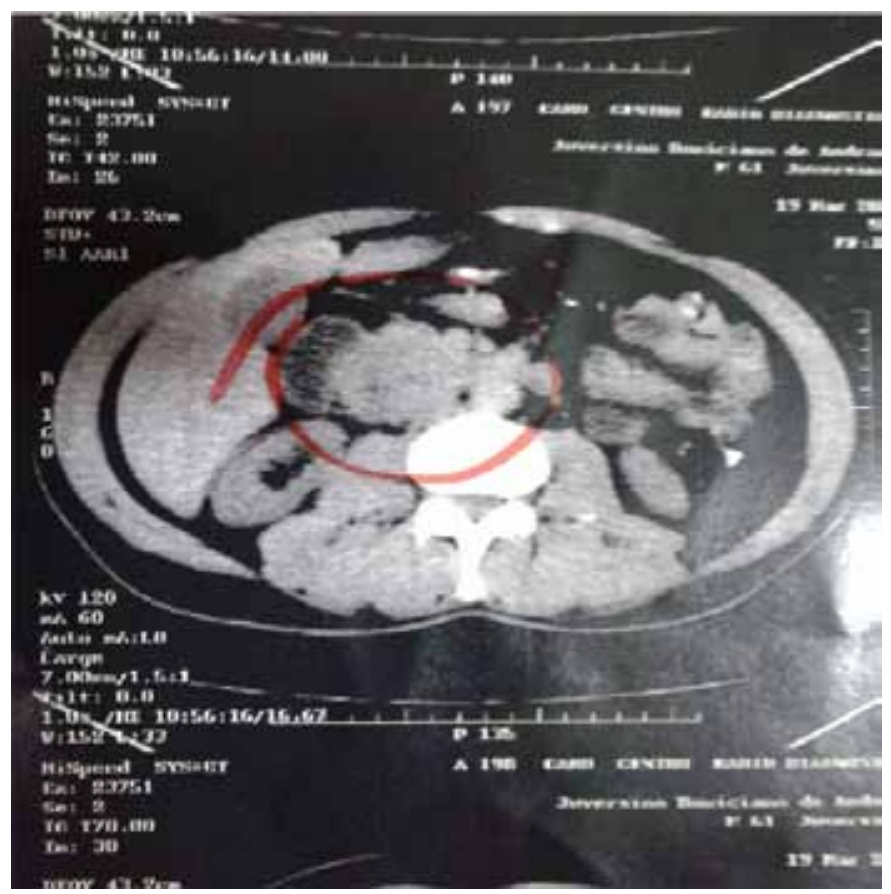

Figure 1: A well-defined lesion in pancreatic head on the abdominal tomography. characteristics (Figure 2). The patient was undergone complete resection of the pancreatic head tumor with enucleation. The postoperative period was uneventful. Presently, the patient is alive and in good health 24 months after surgery, without signs of recurrence.

Histopathological findings: On the macroscopic evaluation of the sagittal specimen there was a brownish tumor mass with finely granular homogeneous surface and hemorrhagic areas (Figure 3). At low magnification the neoplasm was composed of vessels of varying caliber and form between spindle cell stroma and tubular cores surrounded by acidophilic cytoplasm and focally vacuolated (Figure 4). Stromal cells were elongated with myoid tubular or elliptical core, surrounded by focally acidophilus vacuolated cytoplasm surrounding blood vessels to the endothelial basement membrane (Figure 5)

The immunohistochemical panel showed the lesion diffusely positive for vimentin antibodies, $\mathrm{CD} 34$ positive vessels, calretinin and focally positive for cytoplasmic actinin smooth muscle cells, finally MIB-1 (Ki 76) was positive in less than $5 \%$ of the tumor cells (Figures 6 and 7 ).

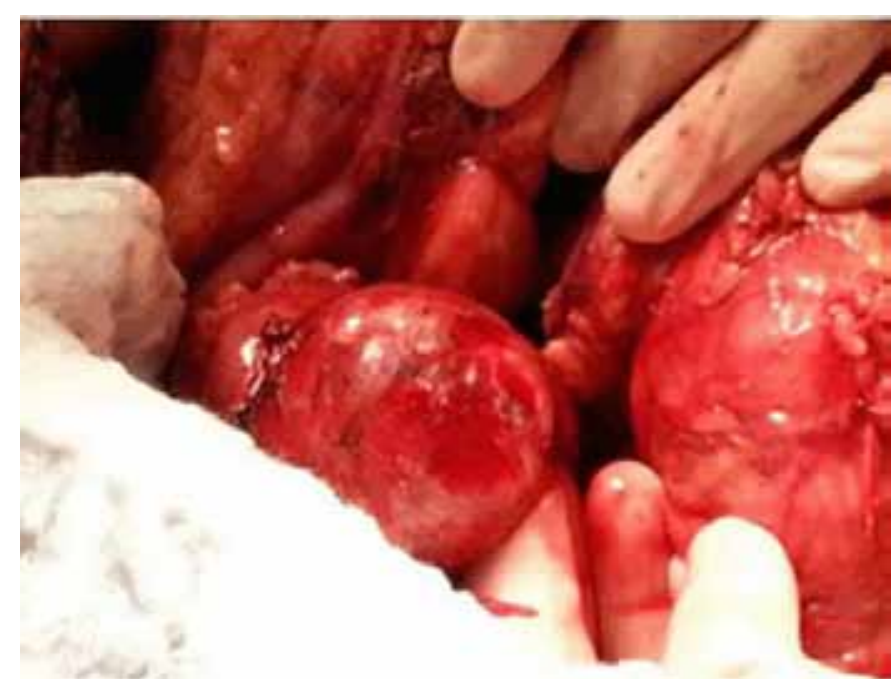

Figure 2: Surgical view of pancreatic head tumor enucleation.

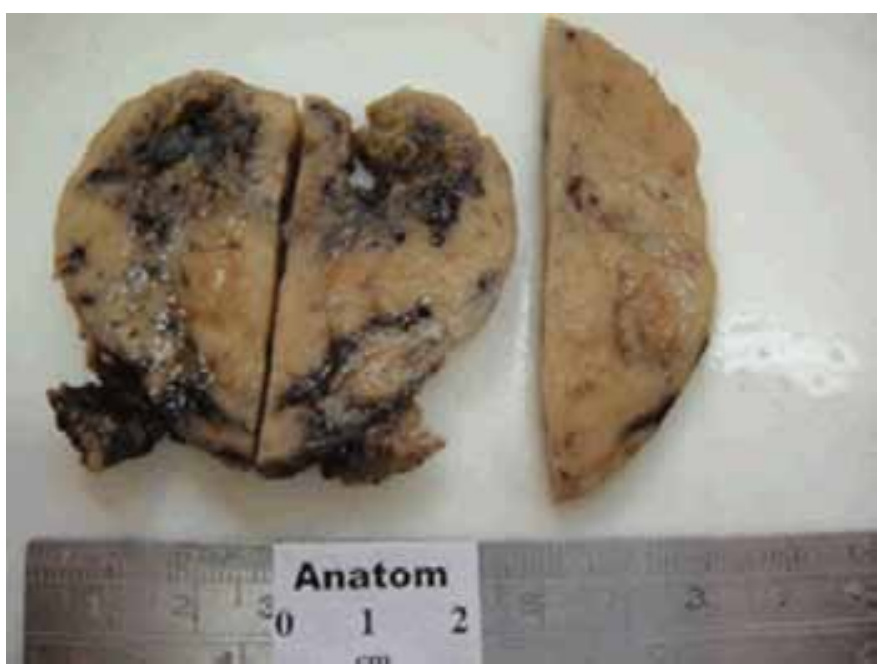

Figure 3: The sagittal specimen on macroscopic evaluation. 


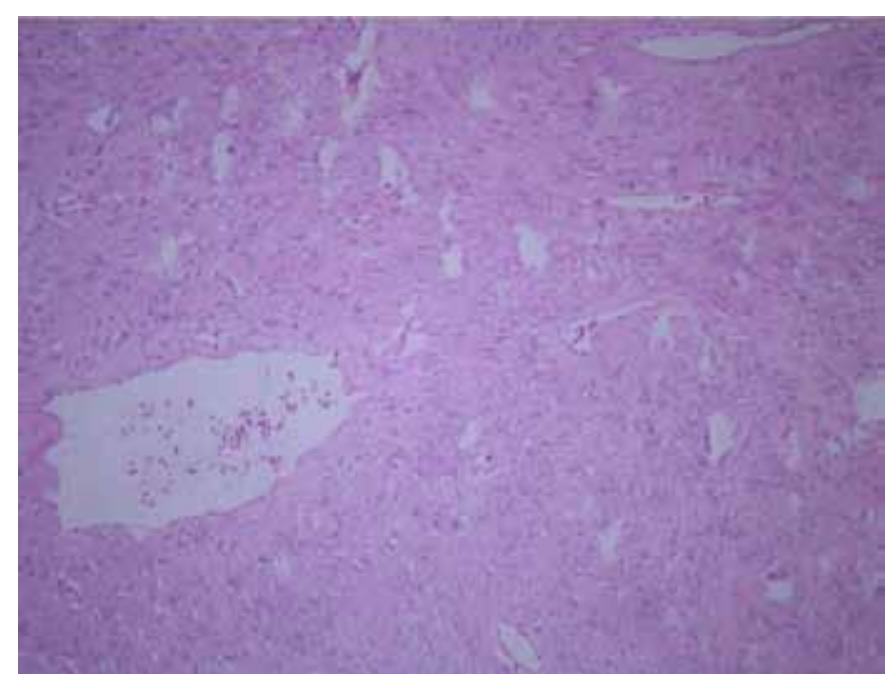

Figure 4: Vessels of varying caliber at low magnification (H\&E stain, x200).

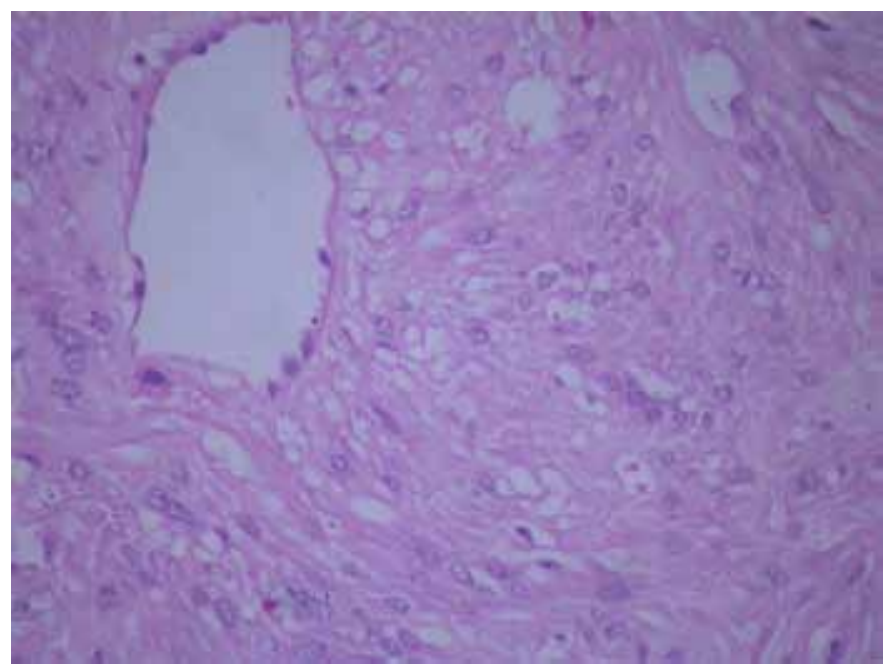

Figure 5: Elongated stromal cells with myoid tubular or elliptical core (H\&E stain, x100).

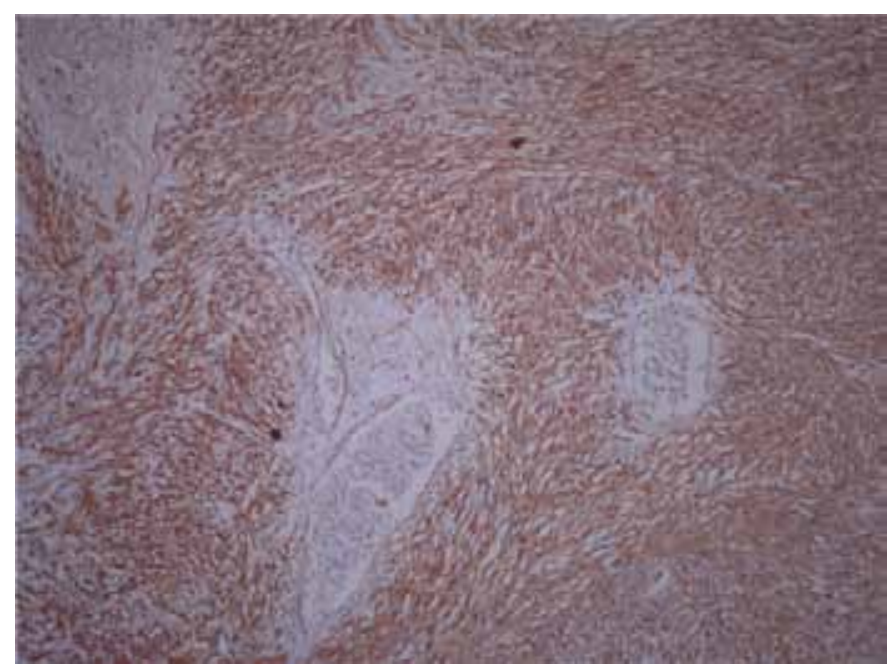

Figure 6: Vimentin antibody with diffuse and intense expression in cytoplasmic and membrane pattern (H\&E stain, 100x).

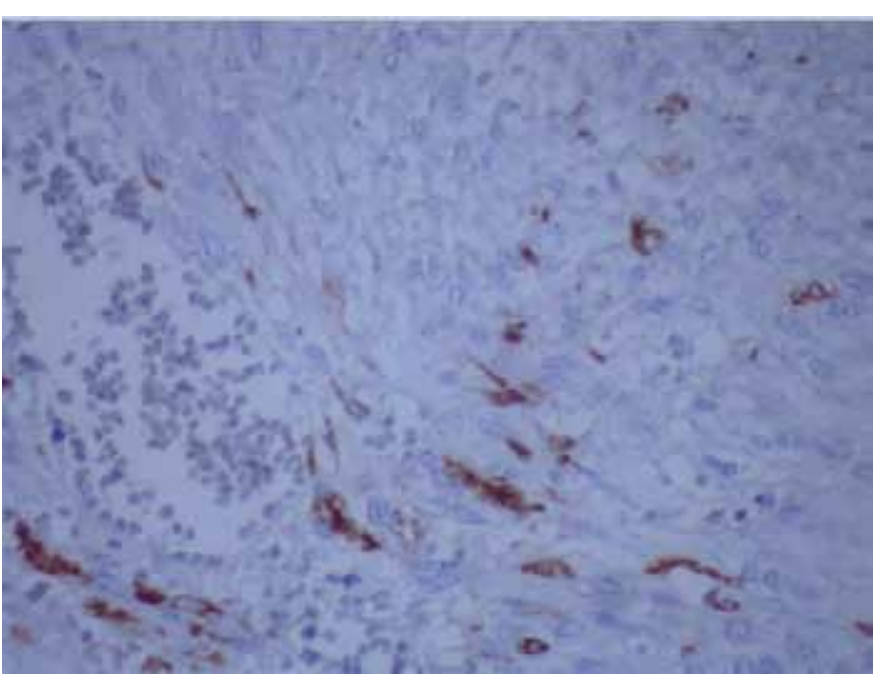

Figure 7: Smooth muscle actin and focal intense cytoplasmic pattern (H\&E stain, 400x).

\section{DISCUSSION}

Soft tissue tumors are rare in the pancreas [7], while glomus tumors are extraordinarily rare as a primary pancreatic neoplasm, but they have been reported in numerous organs [2, 8]. Glomangiomyoma is the least common of the three glomus tumor groups: (1) solid (proper) type, (2) glomangioma and (3) glomangiomyoma [1]. We report the second case in English Literature of a glomangiomyoma in the pancreas of a 65 -year-old male. The rarest variant of glomus tumor was $8 \mathrm{~cm}$ in diameter and the treatment consisted of tumor enucleation, the patient is alive with no evidence of recurrence nine months after surgery. In the first case reported by Miliauskas [6], the patient was younger, a 17-year-old female with a lesion of $5 \mathrm{~cm}$ in diameter successfully treated by resection.

The pancreaticglomangiomyoma reported in this study had an immunohistochemical profile similar to those reported in other sites $[1,3,9]$. There was prominent staining of the glomus cells with muscle-specific actin, smooth muscle actin and vimentin. No reaction has been noted with cytokeratin, EMA, chromogranin, synaptophysin, S100, or HMB45. Reactivity for desmin is variable in glomus tumors, no reaction with desmin has been reported in several studies $[5,6]$, but in others there was some positivity [9]. In one study [10], there was focal positivity with $\mathrm{CD} 34$ but it is generally non-reactive.

The differential diagnoses considered in this case were angiomyoma and angiomyolipoma. Against the diagnosis of angiomyolipoma was the absence of any adipose tissue in multiple sections examined and the lack of reactivity with HMB45. Against the diagnosis of angiomyoma was the presence of prominent foci of rounded glomus cells. The presence of a glomangiomyoma (glomus tumor) in the pancreas raises a number of possibilities in regards to 
its origin. Glomus bodies have been occasionally found in other sites, but not in the pancreas [2, 8]. Glomus tumor (glomangiomyoma) can be added to the list of unusual benign mesenchymal tumors of the pancreas.

\section{CONCLUSION}

Glomangiomyoma is a tumor that mainly affects the lower limbs, but in rare cases, as reported, can affect other structures, such as the pancreatic head. These lesions can be considered in the differential diagnoses of patients with epigastric pain, postprandial vomiting and weight loss, and after diagnosis the surgical treatment with enucleation can be potentially curative.

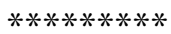

\section{Acknowledgements}

We would also like to specifically thank the contribution of Mr. Alexandre Galvão Bueno, chief of the department of histopathology of the Anatom Laboratory, who also has been involved with this case and who provided many of the photographs used in the this article.

\section{Author Contributions}

Luis Cesar Bredt - Substantial contributions of Conception and design, Acquisition of data, Critical revision of the article, Final approval of the version to be published

Andre Keijy Kajimura Petri - Acquisition of data, Analysis and interpretation of data, Critical revision of the article, Final approval of the version to be published

Fernanda Ezure Bredt - Acquisition of data, Drafting the article, Final approval of the version to be published

Ellan Giulianno Ferreira - Substantial contributions of Conception and design, Acquisition of data, Analysis and interpretation of data, Drafting the article, Final approval of the version to be published

Tiago Cesar Mierzwa - Substantial contributions of Conception and design, Acquisition of data, Analysis and interpretation of data, Drafting the article, Final approval of the version to be published

Milton Neckel Junior - Substantial contributions of Conception and design, Acquisition of data, Analysis and interpretation of data, Drafting the article, Final approval of the version to be published

\section{Guarantor}

The corresponding author is the guarantor of submission.

\section{Conflict of Interest}

Authors declare no conflict of interest.

\section{Copyright}

(C) 2014 Luis Cesar Bredt et al. This article is distributed under the terms of Creative Commons Attribution License which permits unrestricted use, distribution and reproduction in any medium provided the original author(s) and original publisher are properly credited. Please see the copyright policy on the journal website for more information.

\section{REFERENCES}

1. Oizumi S, Kon Y, Ishida $\mathrm{T}$, et al. A rare case of bronchial glomus tumor. Respiration 2001;68(1):958.

2. Heys SD, Brittenden J, Atkinson P, Eremin O. Glomus tumour: An analysis of 43 patients and review of the literature. Br J Surg 1992 Apr;79(4):345-7.

3. Koss MN, Hochholzer L, Moran CA. Primary pulmonary glomus tumour: A clinicopathologic and immunohistochemical study of two cases. Mod Pathol 1998 Mar;11(3):253-8.

4. Masson P. Le glomus neuromyoarteriel des regions tactiles et ses tumeurs. Lyon Chir 1924;21:257-80.

5. García-Prats MD, Sotelo-Rodríguez MT, Ballestín $\mathrm{C}$, et al. Glomus tumours of the trachea: A report of a case with microscopic, ultrastructurally, immunohistochemical examination and review of the literature. Histopathology 1991 Nov;19(5):459-64.

6. Miliauskas JR, Worthley C, Allen PW. Glomangiomyoma (glomus tumour) of the pancreas: A case report. Pathology 2002 Apr;34(2):193-5.

7. Solcia E, Capella C, Hoppel G. Atlas of Tumor Pathology. Tumors of the Pancreas. 3rd series, Fascicle 20. Washington, DC: AFIP, 1997;221.

8. Sunderraj S, Al-Khalifa AA, Pal AK, Pim HP, Sabri SH. Primary intra-osseous glomus tumour. Histopathology 1989 May;14(5):532-6.

9. Nuovo MA, Grimes MM, Knowles DM. Glomus tumours: A clinicopathologic and immunohistochemical analysis of 40 cases. Surg Pathol 1990;3:31-45.

10. Chu PG, Chang KL, Wu AY, Weiss LM. Nasal glomus tumours: Report of two cases with emphasis on immunohistochemical features and differential diagnosis. Hum Pathol 1999 Oct;30(10):1259-61. 
Access full text article on other devices

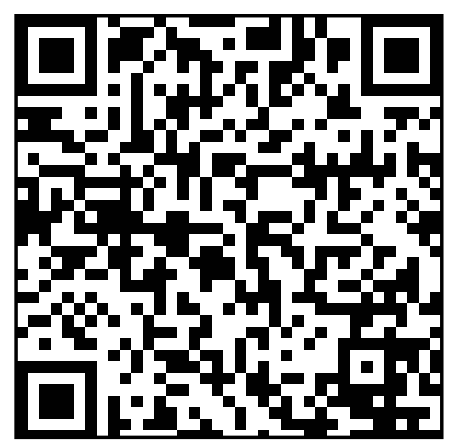

Access PDF of article on other devices

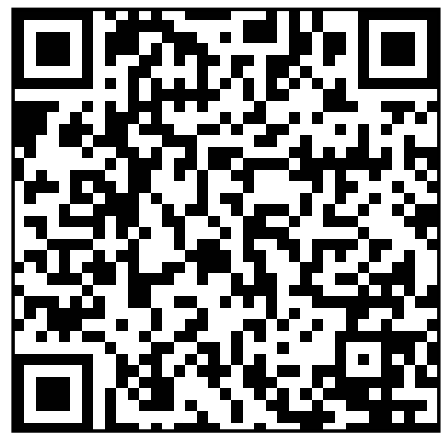

